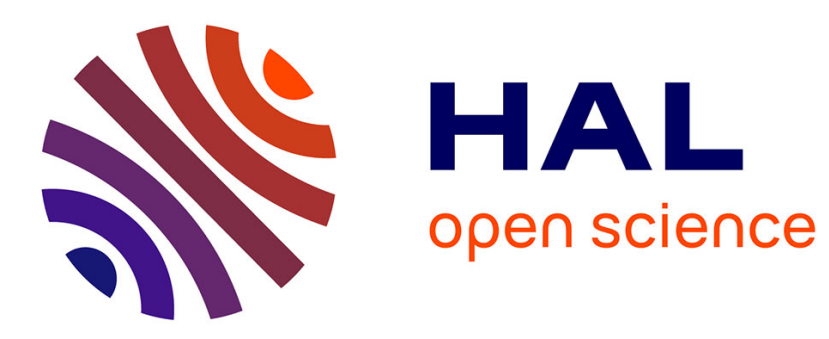

\title{
Controlling disorder and superconductivity in titanium oxynitride nanoribbons with anion exchange
}

Melita Sluban, Polona Umek, Zvonko Jagličić, Jože Buh, Petra Šmitek, Aleš

Mrzel, Carla Bittencourt, Peter Guttmann, Marie-Hélène Delville, Dragan

Mihailović, et al.

\section{To cite this version:}

Melita Sluban, Polona Umek, Zvonko Jagličić, Jože Buh, Petra Šmitek, et al.. Controlling disorder and superconductivity in titanium oxynitride nanoribbons with anion exchange. ACS Nano, 2015, 9 (10), pp.10133-10141. 10.1021/acsnano.5b03742 . hal-01225669

\section{HAL Id: hal-01225669 \\ https://hal.science/hal-01225669}

Submitted on 29 Jan 2021

HAL is a multi-disciplinary open access archive for the deposit and dissemination of scientific research documents, whether they are published or not. The documents may come from teaching and research institutions in France or abroad, or from public or private research centers.
L'archive ouverte pluridisciplinaire HAL, est destinée au dépôt et à la diffusion de documents scientifiques de niveau recherche, publiés ou non, émanant des établissements d'enseignement et de recherche français ou étrangers, des laboratoires publics ou privés. 


\section{Controlling Disorder and Superconductivity in}

\section{Titanium Oxynitride Nanoribbons with Anion}

\section{Exchange}

Melita Sluban, ${ }^{1,2}$ Polona Umek, ${ }^{1}$ Zvonko Jagličici,,${ }^{3,4}$ Jože Buh, ${ }^{1}$ Petra Šmitek, ${ }^{1}$ Aleš Mrzel, ${ }^{1}$ Carla

Bittencourt, ${ }^{5}$ Peter Guttmann, ${ }^{6}$ Marie-Helene Delville, ${ }^{7}$ Dragan Mihailović, ${ }^{1}$ Denis Arčon ${ }^{1,8, *}$

${ }^{1}$ Jožef Stefan Institute, Jamova cesta 39, SI-1000 Ljubljana, Slovenia

${ }^{2}$ Jožef Stefan International Postgraduate School, Jamova cesta 39, SI-1000 Ljubljana, Slovenia

${ }^{3}$ Faculty of Civil and Geodetic Engineering, University of Ljubljana, Jamova cesta 2, SI-1000

Ljubljana, Slovenia

${ }^{4}$ Institute of Mathematics, Physics and Mechanics, Jadranska cesta 19, SI-1000 Ljubljana,

Slovenia

${ }^{5}$ Chimie des Interactions Plasma Surface, CIRMAP, Université de Mons, 20 Place du Parc, B7000 Mons, Belgium

${ }^{6}$ Helmholtz-Zentrum Berlin für Materialien und Energie GmbH, Institute for Soft Matter and Functional Materials, Albert-Einstein-Str. 15, D-12489 Berlin, Germany 
${ }^{7}$ CNRS, Univ. Bordeaux, ICMCB, UPR 9048, 87 Avenue du Dr Schweitzer, F-33608 Pessac Cedex, France

${ }^{8}$ Faculty of Mathematics and Physics, University of Ljubljana, Jadranska cesta 19, SI-1000 Ljubljana, Slovenia

KEYWORDS: titanium oxynitride, nanoribbons, anion exchange, Kirkendall effect, disorder, superconductivity

\begin{abstract}
In recent years, conversion chemical reactions, which are driven by the ion diffusion emerged as an important concept for formation of nanoparticles. Here we demonstrate that the slow anion diffusion in anion exchange reactions can be efficiently used to tune the disorder strength and the related electronic properties of nanoparticles. This new paradigm is applied to high-temperature formation of titanium oxynitride nanoribbons, $\mathrm{Ti}(\mathrm{O}, \mathrm{N})$, transformed from hydrogen titanate nanoribbons in an ammonia atmosphere. The nitrogen content, which determines the chemical disorder through random $\mathrm{O} / \mathrm{N}$ occupancy and ion vacancies in the $\mathrm{Ti}(\mathrm{O}, \mathrm{N})$ composition, increases with the reaction time. The presence of disorder has paramount effects on resistivity of $\mathrm{Ti}(\mathrm{O}, \mathrm{N})$ nanoribbons. Atypically for metals, the resistivity increases with decreasing temperature due to the weak localization effects. From this state superconductivity develops below considerably or completely suppressed critical temperatures, depending on the disorder strength. Our results thus establish the remarkable versatility of anion exchange for tuning of the
\end{abstract}


electronic properties of $\operatorname{Ti}(\mathrm{O}, \mathrm{N})$ nanoribbons and suggest that similar strategies may be applied to a vast number of nanostructures.

Conversion chemistry has emerged as an important field for the guided formation of nanoparticles. Frequently, the chemical conversion in nanoparticles is guided by the ion diffusion processes, as is the case with the nanoscale Kirkendall effect ${ }^{1-10}$ or anion exchange, which is also often accompanied by the Kirkendall effect. ${ }^{11-14}$ The nanoscale Kirkendall effect typically yields hollow metal nanostructures, e.g., in the transformation of nanoparticles from the solid Co into the hollow $\operatorname{CoS},{ }^{1,7}$ the oxidation of nickel nanoparticles ${ }^{8}$ or the synthesis of copper oxide nanotubes. ${ }^{9}$ On the other hand, in anion exchange reactions the morphology of the nanoparticles may be less affected, although it requires long reaction times and high reaction temperatures because anions generally diffuse slowly. ${ }^{14}$ Both type of reactions stem from the considerable difference in diffusion rates of ions and ion vacancy migration, which balances the directional flow of matter and creates voids in nanoparticles. As such, these reactions inevitably introduce disorder and one can propose that by stopping the conversion at different stages, one would control not only the morphology but also the disorder strength and the related structural and electronic properties of nanoparticles.

Titanium nitride, TiN, is a ceramic with metallic conductivity and is mostly utilized as a hard coating material because of its hardness and chemical stability. ${ }^{15}$ Interestingly, TiN is also a conventional superconductor with the critical temperature, $T_{\mathrm{c}}$, of $5.6 \mathrm{~K}$ when measured in highquality bulk samples. ${ }^{16}$ The critical temperature depends on the degree of disorder, ${ }^{17-20}$ which can in thin films trigger the disorder-driven superconductor-to-insulator transition. ${ }^{21,22}$ Different 
degrees of disorder thus provide a plethora of electronic states, in which the structural and electronic flexibility of TiN structures opens up new possibilities for switching from the insulating/semiconducting to the metallic/superconducting state in a systematic and controllable way, purely by tuning the disorder strength.

Numerous $\mathrm{TiO}_{2}$ and titanate phases, which can be easily prepared in the form of nanoparticles, are prototypical wide-gap semiconductors and may even display room-temperature ferromagnetism upon doping. ${ }^{23-26} \mathrm{TiO}_{2}$ transforms to titanium oxynitride, $\mathrm{Ti}(\mathrm{O}, \mathrm{N})$, in a dynamic ammonia atmosphere at temperatures above $600{ }^{\circ} \mathrm{C} .{ }^{27}$ Moreover, the nitridation of potassium titanate nanowires in an ammonia atmosphere leads to formation of $\mathrm{Ti}(\mathrm{O}, \mathrm{N})$ nanotubes, ${ }^{28}$ which may imply that the transformation proceeds via the nanoscale Kirkendall mechanism. Since hydrogen titanate nanoribbons (HTiNRs) can be easily prepared in a very pure form and in macroscopic quantities, ${ }^{29,30}$ they are the ideal starting material for the transformation to the $\mathrm{Ti}(\mathrm{O}, \mathrm{N})$ nanostructures in an ammonia atmosphere. ${ }^{30}$ Here we report that this transformation is indeed based on anion exchange possibly accompanied by the Kirkendall effect. By varying the reaction conditions, i.e. the reaction time and the ammonia flow, we can achieve nearly continuous variation of the nitrogen content, which defines the degree of disorder through random $\mathrm{O} / \mathrm{N}$ occupancy and concentration of ion vacancies in the $\mathrm{Ti}(\mathrm{O}, \mathrm{N})$ chemical composition - both serve as an efficient disorder-strength control of the electronic ground state. The presence of disorder is reflected in a suppressed density of states and the weak-localization corrections ${ }^{31,32}$ to the nanoribbon's resistivity. Whereas superconductivity at reduced $T_{\mathrm{c}}$ is still observed in $\mathrm{Ti}(\mathrm{O}, \mathrm{N})$ nanoribbons with weak disorder, a disorder-driven transition to non-superconducting poorly-conducting state is observed as the disorder becomes stronger with the decreasing nitridation level. This central finding of our work offers an intriguing possibility for research of 
disorder-controlled interplay between antagonistic insulating and superconducting orders in nanoparticles.

\section{RESTULS AND DISCUSSION}

\section{Transformation to titanium oxynitride nanoribbons}

Crystalline hydrogen titanate nanoribbons ${ }^{29,30}$ (HTiNRs, Fig. S1) of average thickness, width and length of $20 \mathrm{~nm}, 40-250 \mathrm{~nm}$ and $0.5-3 \mu \mathrm{m}$ respectively, were used as the precursor material for the synthesis of titanium oxynitride nanoribbons $(\mathrm{Ti}(\mathrm{O}, \mathrm{N}) \mathrm{NRs})$. The reaction in $\mathrm{NH}_{3}(\mathrm{~g})$ flow proceeds in two stages. In the first stage, thermally unstable HTiNRs at $800{ }^{\circ} \mathrm{C}$ completely transform to $\mathrm{TiO}_{2}$, i.e. $\mathrm{H}_{2} \mathrm{Ti}_{3} \mathrm{O}_{7}(\mathrm{~s}) \rightarrow 3 \mathrm{TiO}_{2}(\mathrm{~s})+\mathrm{H}_{2} \mathrm{O}$ (g) (Fig. S2). During this transformation, the $\mathrm{H}_{2} \mathrm{O}$ molecules that leave the structure create mesopores with diameters in the range of few $\mathrm{nm}$ in the nanoribbon. ${ }^{30,33}$ In the second stage, i.e. the nitridation stage, $\mathrm{TiO}_{2}$ converts to titanium oxynitride, $\mathrm{Ti}(\mathrm{O}, \mathrm{N})_{x}(x \approx 1)$ by substituting oxygen with nitrogen atoms: $\mathrm{TiO}_{2}(\mathrm{~s})+\mathrm{NH}_{3}(\mathrm{~g}) \rightarrow$ $\mathrm{Ti}(\mathrm{O}, \mathrm{N})_{\mathrm{x}}(\mathrm{s})+\mathrm{H}_{2} \mathrm{O}(\mathrm{g}){ }^{34}$

Since the nitridation process is a nitrogen diffusion-controlled reaction ${ }^{28,35,36}$, the nitrogen content in $\operatorname{Ti}(\mathrm{O}, \mathrm{N})$ nanoribbons can be controlled by varying the reaction parameters. Therefore, we set the same temperature of $800{ }^{\circ} \mathrm{C}$ for all nitridation reactions, but used different values of $\mathrm{NH}_{3}(\mathrm{~g})$ flow while systematically changing the reaction times (Table $\mathrm{S} 1$ ). We note at this point that the prepared samples were labeled as TiON-t/f, where $t$ refers to the reaction time in hours and $\boldsymbol{f}$ to the value of $\mathrm{NH}_{3}(\mathrm{~g})$ flow in $\mathrm{mL} / \mathrm{min}$. Samples treated for $4 \mathrm{~h}$ or more in $25 \mathrm{~mL} / \mathrm{min}$ $\mathrm{NH}_{3}(\mathrm{~g})$ flow show powder X-ray diffraction (XRD) peaks (Figs. 1a and S2) that are all indexed to the cubic $\mathrm{Ti}(\mathrm{O}, \mathrm{N})$ structure (space group $F m \overline{3} m$ ). No traces of titanate or titania peaks were noticed in the measured XRD patterns, confirming the complete transformation to the titanium 
oxynitride phase. The minimum required time for a complete conversion to $\operatorname{Ti}(\mathrm{O}, \mathrm{N})$ structure decreased to $3 \mathrm{~h}$ if a higher $\mathrm{NH}_{3}(\mathrm{~g})$ flow of $30 \mathrm{~mL} / \mathrm{min}$ was used. The time was even shortened to 40 minutes in a control experiment with the highest flow rate of $150 \mathrm{~mL} / \mathrm{min}$ (Table S1).

a

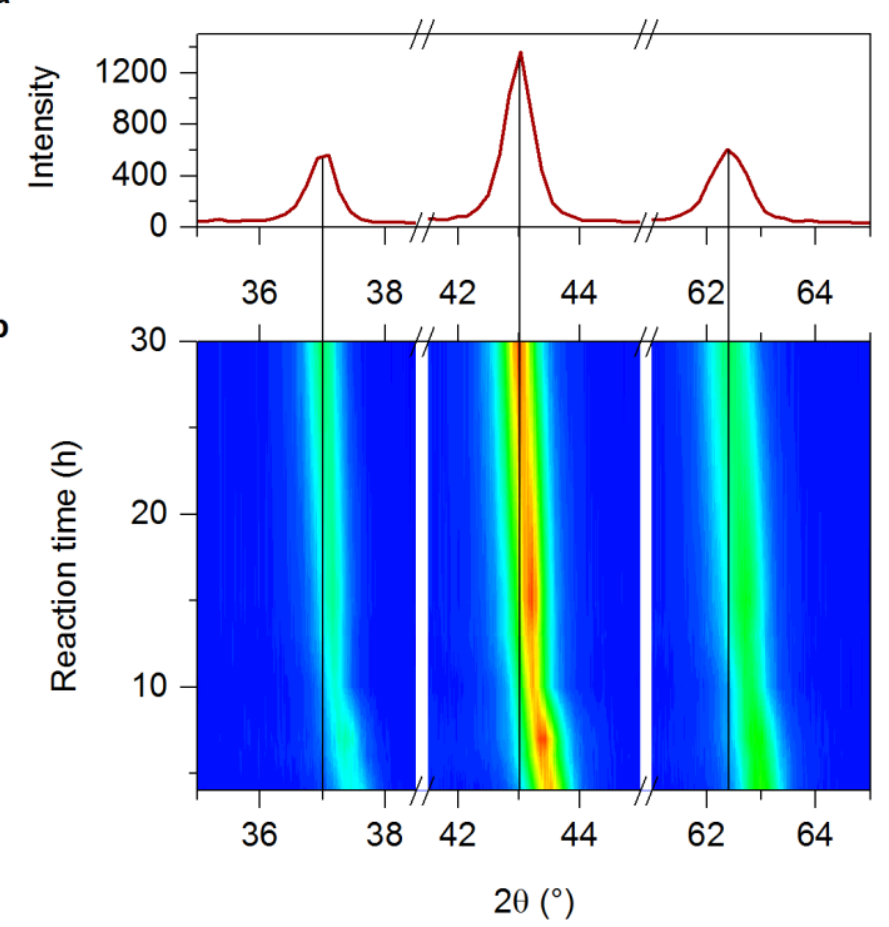

C

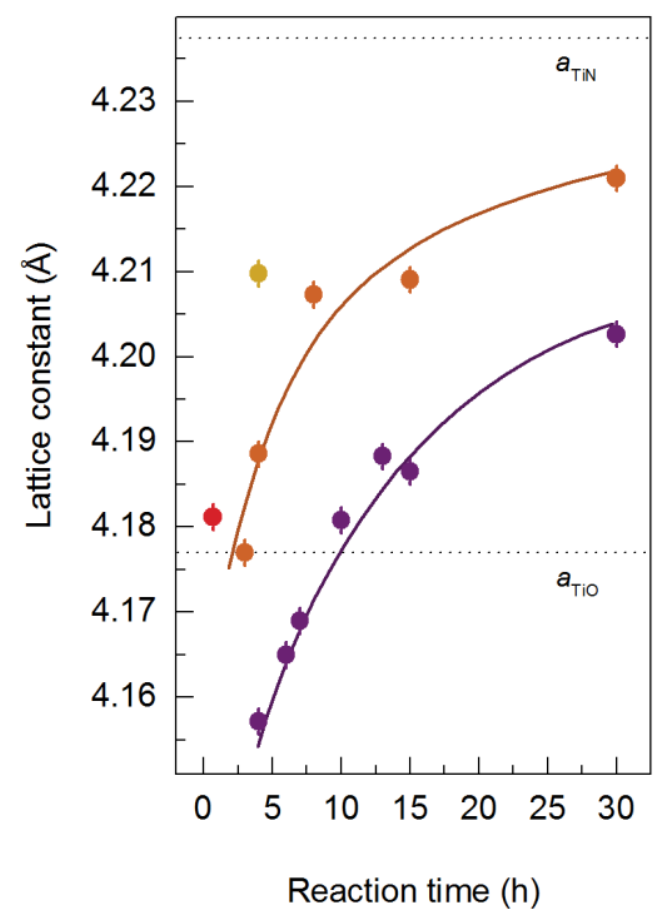

Figure 1. Evolution of titanium oxynitride structure with the reaction time. a, Room temperature powder X-ray diffraction profile of the TiON-30/25 sample, which was treated for $30 \mathrm{~h}$ in 25 $\mathrm{mL} / \mathrm{min} \mathrm{NH}_{3}(\mathrm{~g})$ flow at $800{ }^{\circ} \mathrm{C}$. The $2 \theta$ scale is expanded around the centers of the three main peaks, corresponding to (111), (200) and (220) reflections of the $F m \overline{3} m$ structure. b, The evolution of the three powder X-ray diffraction peaks, measured as a function of the reaction time ranging from $4 \mathrm{~h}$ to $30 \mathrm{~h}$. For all samples, the reaction took place in $25 \mathrm{~mL} / \mathrm{min} \mathrm{NH}_{3}(\mathrm{~g})$ flow and at the set temperature of $800{ }^{\circ} \mathrm{C}$. c, The dependence of cubic lattice constant on the reaction time for experiments in $25 \mathrm{~mL} / \mathrm{min}(\bullet), 30 \mathrm{~mL} / \mathrm{min}(\bullet), 100 \mathrm{~mL} / \mathrm{min}(\bullet)$ and 150 
$\mathrm{mL} / \mathrm{min}(\bullet)$ flow of $\mathrm{NH}_{3}(\mathrm{~g})$. Solid lines are guides to the eye. Dashed horizontal lines mark the lattice constants of TiN and TiO structures, respectively.

With increasing reaction times, a noticeable shift of diffraction peaks towards lower $2 \theta$ values is observed (Figs. 1b and S2). The extracted cubic lattice parameter systematically increases with the increasing nitridation time and with the $\mathrm{NH}_{3}(\mathrm{~g})$ flow (Fig. 1c, Table S2) approaching the largest value of $a=4.221 \AA$ for the sample treated for $30 \mathrm{~h}$ in the $\mathrm{NH}_{3}(\mathrm{~g})$ flow set to $30 \mathrm{~mL} / \mathrm{min}$, TiON-30/30. However, even for this sample the lattice parameter is still significantly smaller than the corresponding value of the cubic TiN (Aldrich), $a=4.2374 \AA$. At shorter nitridation times, $a$ becomes comparable to that of TiO (JCPDS card No. 08-117), $a=4.177 \AA$, being thus consistent with the lower $\mathrm{N}$ content in the structure of the Ti(O,N) nanoribbons. Strikingly, the samples nitridated for the shortest times, e.g. at reaction times between 4 and $7 \mathrm{~h}(\mathbf{T i O N}-\mathbf{4} / \mathbf{2 5}$, TiON-6/25 and TiON-7/25), have $a$ even smaller than TiO (Table S2). The early stage incomplete nitrogen substitution at the oxygen sites of $\mathrm{TiO}_{2}$ creates many ion vacancies ${ }^{37}$, which are, with an increasing reaction time, gradually occupied by the slowly incoming nitrogen species. The samples nitridated for the shortest times thus show a considerable degree of disorder associated, not only with the random $\mathrm{O} / \mathrm{N}$ occupancy, but also with the off-stoichiometry - the samples are indeed best described as $\mathrm{TiO}_{x} \mathrm{~N}_{y}$ with $x+y \approx 1$.

During the transformation from $\mathrm{TiO}_{2}$ (anatase) to $\mathrm{Ti}(\mathrm{O}, \mathrm{N})$ phase the nanoribbon morphology is retained (Fig. S1). However, the average nanoribbon diameter increases with increasing reaction time as it can be deduced from the statistical analysis of TEM images (Fig. S3). The well-defined crystal facets of the parent material (Fig. S1c) were also affected during the thermal treatment as numerous channels protruding nanoribbons, with diameters in the range of $20-50$ 
nm, can be clearly seen (Fig. 2). Moreover, their size increases with longer reaction times for the set of samples synthesized at the same value of $\mathrm{NH}_{3}(\mathrm{~g})$ flow (Fig. 2). The presence of ion vacancies found in the XRD studies indicates that the diffusion rates of oxide and nitride anions are different. If a smaller oxide anion has a higher diffusion rate compared to a larger nitride anion and if the exchange of these two species proceeds through the surface of mesopores, which emerge at the first stage of the transformation of hydrogen titanate to $\mathrm{TiO}_{2}$ phase ${ }^{30,33}$, then the ion vacancies will supersaturate and finally coalesce to create the larger channels.
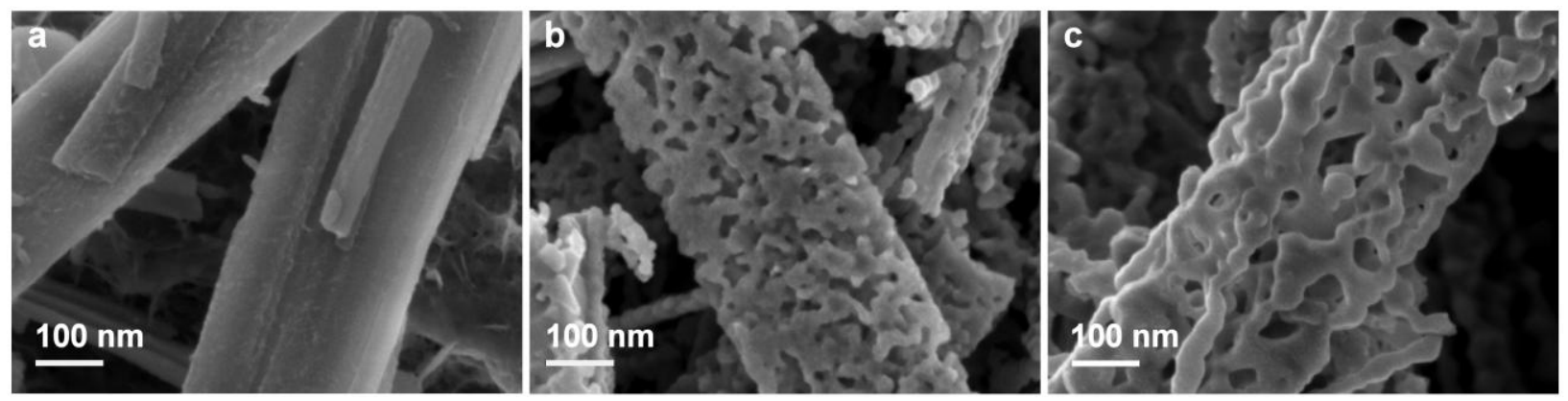

Figure 2. Morphology evolution of the $\mathrm{Ti}(\mathrm{O}, \mathrm{N})$ nanoribbons with the reaction time. Scanning electron microscopy images of the precursor hydrogen titanate nanoribbons (a) and titanium oxynitride nanoribbons derived after calcination at $800{ }^{\circ} \mathrm{C}$ in a flow of ammonia of $30 \mathrm{~mL} / \mathrm{min}$ for $4 \mathrm{~h}$ (b) and $30 \mathrm{~h} \mathrm{(c).} \mathrm{The} \mathrm{nanoribbons} \mathrm{with} \mathrm{similar} \mathrm{diameters} \mathrm{of} \mathrm{about} \sim 250 \mathrm{~nm}$ were selected for easier comparison.

By calculating the Fourier transform of patterns in the marked areas of high resolution transmission electron microscopy (HRTEM) images (Fig. S4), we find that the $d$-spacing values (TiON-30/30), which correspond to the (200) plane of the cubic Ti(O,N), slightly vary between 2.10 and $2.12 \AA$. The observed difference confirms the variation in local $\mathrm{O} / \mathrm{N}$ composition at the 
selected areas. Moreover, the local Ti : O : N variation in stoichiometry, which was studied by chemical mapping of $\mathrm{Ti}, \mathrm{O}$ and $\mathrm{N}$ over given regions of interest of an individual nanoribbon (Fig. S5), demonstrate that the relative oxygen concentration increases in the thinnest regions of the nanoribbon (Fig. S5c). Typically, due to the passivation ${ }^{27,40}$ a higher oxygen concentration is detected near the surface of the cavities, disclosing lower nitridation level compared to the thicker (bulk-like) regions of the nanoribbon, where titanium and nitrogen atoms prevail (blue and pink colors in Fig. S5e) over oxygen.

In the gas phase, because of $\mathrm{NH}_{3}(\mathrm{~g})$ thermal decomposition at $800{ }^{\circ} \mathrm{C}$ also $\mathrm{N}_{2}(\mathrm{~g})$ and $\mathrm{H}_{2}(\mathrm{~g})$ are present. Reactions at surface, $\mathrm{Ti}^{4+}$ reduction (Fig. S6) and nitridation, thus probably involve both $\mathrm{NH}_{3}$ and $\mathrm{H}_{2}$ species. ${ }^{39}$ The initial channels in the nanoribbons may emerge either from the lattice mismatch between the parent $\mathrm{TiO}_{2}$ (anatase) and the emerging $\mathrm{Ti}(\mathrm{O}, \mathrm{N})$ phase or due to the ion diffusion processes. After $4 \mathrm{~h}$ of reaction in $\mathrm{NH}_{3}(\mathrm{~g})$ flow set to $25 \mathrm{~mL} / \mathrm{min}$ porous single $\mathrm{Ti}(\mathrm{O}, \mathrm{N})$ phase is obtained (Figs. 1 and S2, Table S2). For longer reaction times the nitridation process is controlled by the diffusion of oxide and nitride anions, and ion vacancies. The increase in nanoribbons porosity in this reaction time-window (Fig. 2) is probably due to the diffusion of ion vacancies and their coalescence. The diffusion controlled reaction together with the presence of ion vacancies, the formation of large channels and the observed increase in the average diameter of the nanoribbons during the reaction may be suggestive of the anion exchange through the Kirkendall effect. ${ }^{14}$ Moreover, occasionally nanoribbons with a hollow structure (Fig. S7) are found, which is another characteristics of the nanoscale Kirkendall effect. We note at this point that there are different factors that may prevent the formation of a perfect hollow core in all nanoribbons, such as specific geometry or richness in defects. ${ }^{10}$ In order to unambiguously determine the conversion mechanism the conversion mechanisms that applies to the studied 
system, in-situ microscopy study of the transformation of $\mathrm{TiO}_{2}$ nanoribbons to $\mathrm{Ti}(\mathrm{O}, \mathrm{N})$ via heating at high temperatures in an $\mathrm{NH}_{3}$ atmosphere has to be conducted.

\section{Disorder and electronic properties of titanium oxynitride nanoribbons}

The N1s X-ray photoelectron spectroscopy (XPS) spectra recorded on three characteristic samples prepared at reaction times of 4,8 and $30 \mathrm{~h}(\mathrm{TiON}-\mathbf{4} / \mathbf{3 0}$, TiON-8/30 and TiON-30/30) are compared in Fig. 3a. In all cases, three components were required to fit the N1s peak. The low intensity broad component at $398.5 \mathrm{eV}$ is recognized as $\mathrm{N}$ bonded to $\mathrm{O}$, which is formed by the terminally bound nitrogen released during the nitridation of the Ti-O sites, most likely in the oxygen rich amorphous regions near the surface of the nanoribbon cavities (Fig. S5). ${ }^{36}$ Since it is extrinsic to the $\mathrm{Ti}(\mathrm{O}, \mathrm{N})$ phase it will not be further discussed here. The component centered at $396.0 \mathrm{eV}$ is assigned ${ }^{36,38}$ to the N-Ti-O linkage, whereas the component at $397.0 \mathrm{eV}$ originates

from the photoemission of $\mathrm{N} 1 \mathrm{~s}$ core level electrons in the fully nitridated TiN structure. ${ }^{38}$ The Ti-N peak systematically increases in intensity with increasing reaction time at the expense of the N-Ti-O peak. The analysis of the relative Ti-N and N-Ti-O peak intensities (Fig. 3a) shows that the N/Ti ratio (Fig. 3b) increased from $0.75(5)$ when the reaction was terminated after $3 \mathrm{~h}$ to $1.10(5)$ after $30 \mathrm{~h}$ of reaction. This finding fully corroborates the smooth increase in the nitridation level with the reaction time and thus accounts for the increase in the lattice parameter (Fig. 1). Complementary analysis of the O1s XPS data enables us to extract the oxygen amount (Table S3). However, we stress that these values are severely affected by the surface passivation. $^{27,40}$ 
a

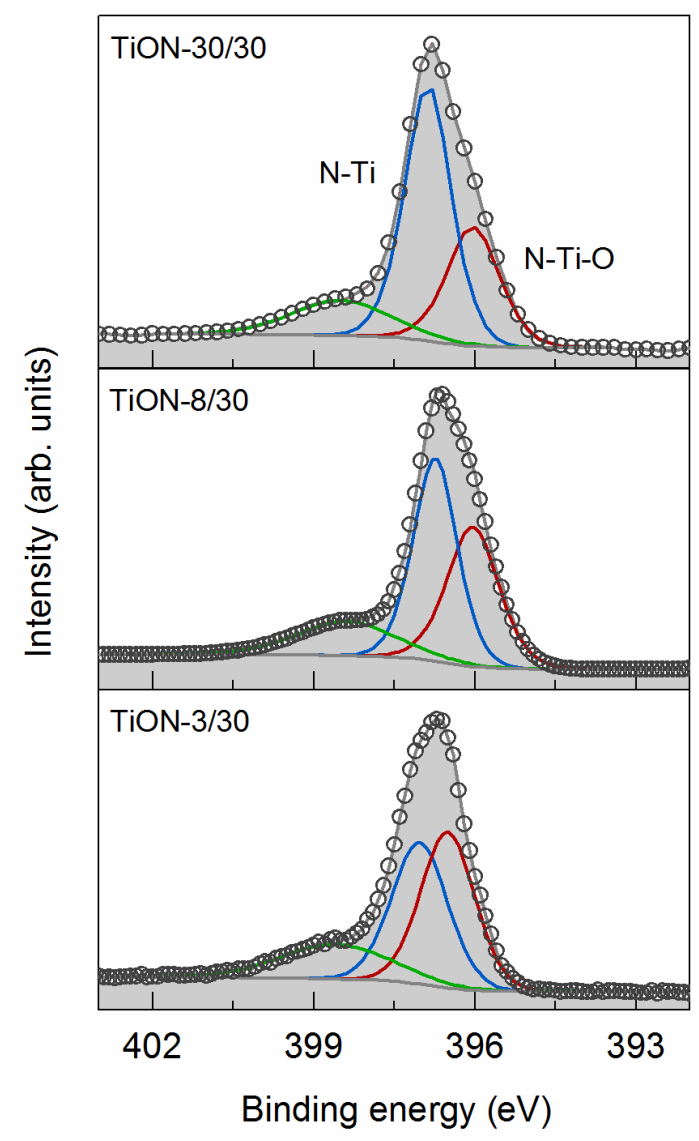

b

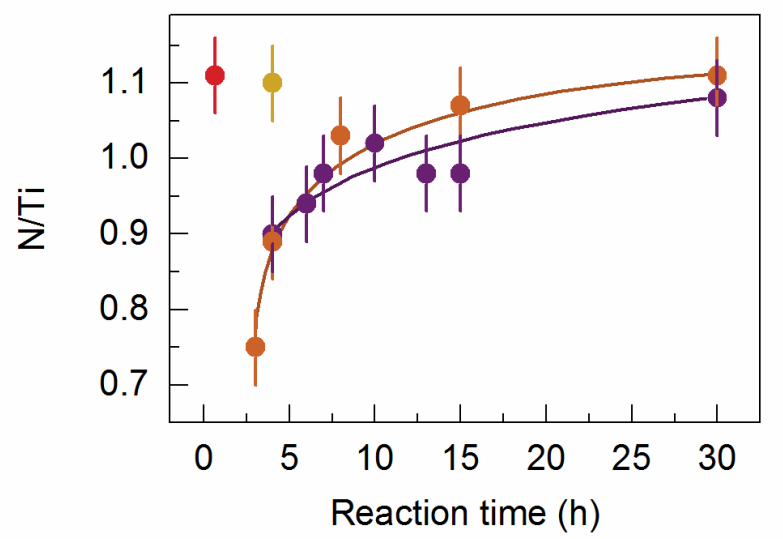

C

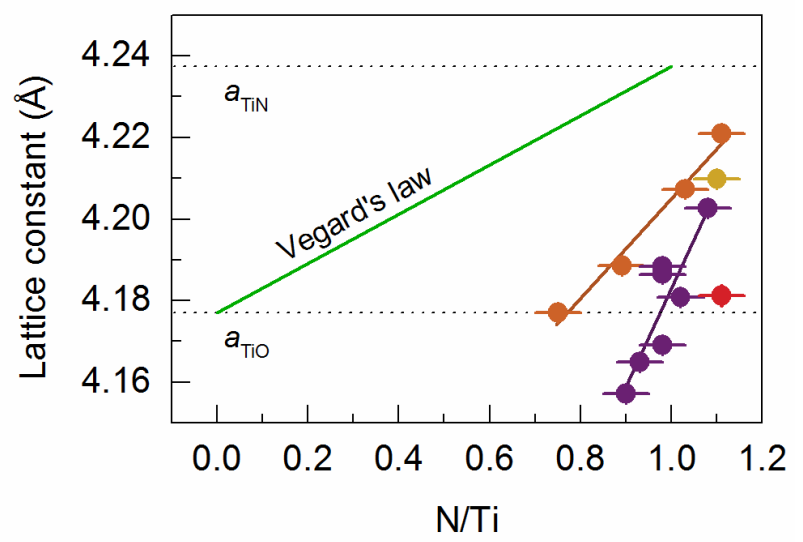

Figure 3. Dependence of the nitridation level on the reaction conditions. a, Nitrogen 1s X-ray photoelectron spectroscopy spectra of titanium oxynitride nanoribons that were treated for 3,8 and $30 \mathrm{~h}$ in $30 \mathrm{~mL} / \mathrm{min} \mathrm{NH}_{3}(\mathrm{~g})$ flow at $800{ }^{\circ} \mathrm{C}$. The spectral deconvolution reveals the presence of the N-Ti-O linkage in regions with incomplete substitutional $\mathrm{N}$ doping (solid red lines), the Ti-N bonds of fully nitridated regions (solid blue lines) and $\mathrm{N}$ bonded to $\mathrm{O}$ in the oxygen rich amorphous regions (solid green lines). $\mathbf{b}$, Dependence of the N/Ti ratio on the reaction time for two different values of the $\mathrm{NH}_{3}(\mathrm{~g})$ flow, $25(\bullet)$ and $30 \mathrm{~mL} / \mathrm{min}(\bullet)$, respectively. We note, that the nitridation level also increases with the increasing ammonia flow as can be deduced from the control experiments (Table S2). The nitridation of 1.11(5) was already achieved after $4 \mathrm{~h}$ or even after $40 \mathrm{~min}$ when higher ammonia flows of $100 \mathrm{~mL} / \mathrm{min}(\bullet)$ and $150 \mathrm{~mL} / \mathrm{min}(\bullet)$ were used in 
the reaction. c, Variation of the lattice constant with the N/Ti ratio for two different values of the $\mathrm{NH}_{3}(\mathrm{~g})$ flow, $25(\bullet)$ and $30 \mathrm{~mL} / \mathrm{min}(\bullet)$, respectively. Solid violet and orange lines are guides to the eye, whereas the solid green line shows the dependence of the lattice constant, which would follow the Vegard's law. Dashed horizontal lines mark the lattice constants of the TiN and TiO structures.

When plotting the lattice parameter $v s$. the nitridation level N/Ti (Fig. 3c), we find that all experimental points markedly deviate from the Vegard's law. With prolonged reaction time the discrepancy becomes smaller thus correlating with the decreasing concentration of ion vacancies. The presence of ion vacancies accounts for the chemical pressure, which reduces the lattice parameter for a given N/Ti ratio. The difference between the lattice parameter calculated from the Vegard's law, $a_{\mathrm{V}}$, and the experimental lattice parameter, $\Delta=a_{\mathrm{V}}-a$, is therefore a direct measure of the disorder strength associated with ion vacancies.

The presence of ion vacancies and the chemical disorder shown by the N/Ti ratio must dramatically affect the electronic properties of nanoribbons, so we next study the magnetic and transport properties of the $\mathrm{Ti}(\mathrm{O}, \mathrm{N})$ nanoribbons. The room-temperature susceptibilities, $\chi$, of the $\mathrm{Ti}(\mathrm{O}, \mathrm{N})$ samples are in the range of $\chi(300 \mathrm{~K})=4 \cdot 10^{-5}-9.5 \cdot 10^{-5} \mathrm{emu} / \mathrm{mol}($ Figs. $4 \mathrm{a}$ and S8). The largest $\chi(300 \mathrm{~K})$ is measured for TiON-4/30 (Fig. 4a). For this sample $\chi(T)$ marginally increases with decreasing temperature down to $T \approx 220 \mathrm{~K}$, but upon further cooling, $\chi(T)$ is suddenly enhanced before it saturates again between $\sim 150$ and $\sim 40 \mathrm{~K}$ at $\chi=2 \cdot 10^{-4} \mathrm{emu} / \mathrm{mol}$. The lowtemperature Curie-like enhancement of $\chi(T)$ detected below $\sim 40 \mathrm{~K}$ is attributed to localized paramagnetic defects, which are present in all samples. Fitting $\chi(T)$ at low temperatures to Curie 
law yields the Curie constant $C=1.7 \cdot 10^{-4} \mathrm{emu} \mathrm{K} / \mathrm{mol}$, which corresponds to the concentration of localized paramagnetic defects of about $\sim 450 \mathrm{ppm}$ in TiON-4/30. Moreover, we observe the splitting in $\chi(T)$ when measuring under the zero-field and the field-cooled protocols and the hysteresis loop in the magnetization measurement at $5 \mathrm{~K}$ (inset to Fig. 4a). Similar behavior, which is indicative of weak ferromagnetic component, is also found in other strongly disordered $\mathrm{Ti}(\mathrm{O}, \mathrm{N})$ samples prepared at short reaction times, showing a small lattice parameter $a<4.19 \AA$ and a large deviation from the Vegard's law $\Delta>0.04 \AA$ (Fig. 3c, Tables S1 and S2). We stress that the ferromagnetic response is completely absent in the diamagnetic parent titanate material, ${ }^{29}$ so it was introduced during the transformation in the $\mathrm{NH}_{3}(\mathrm{~g})$ atmosphere. The weak ferromagnetism is also not detected in the samples prepared at longer reaction times and with $a \geq$ $4.19 \AA$ and $\Delta<0.04 \AA$. However, since the magnitude of the ferromagnetic response depends on the thermal history of the sample, it is not yet clear whether its origin is truly intrinsic to disordered $\mathrm{Ti}(\mathrm{O}, \mathrm{N})$ phase or whether it is extrinsic, resulting from surface magnetism associated with the oxygen rich regions near the surface of the channels (Fig. S5). 
a

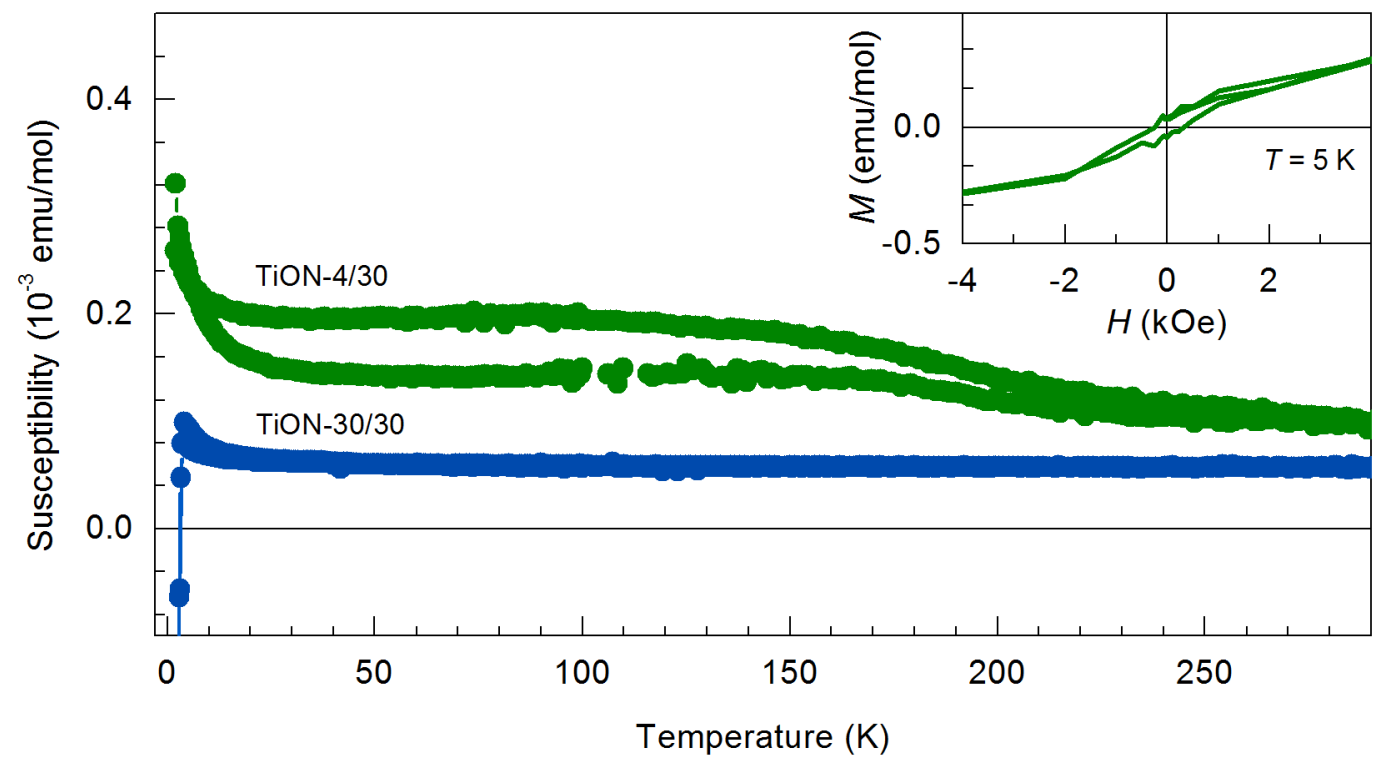

b

C
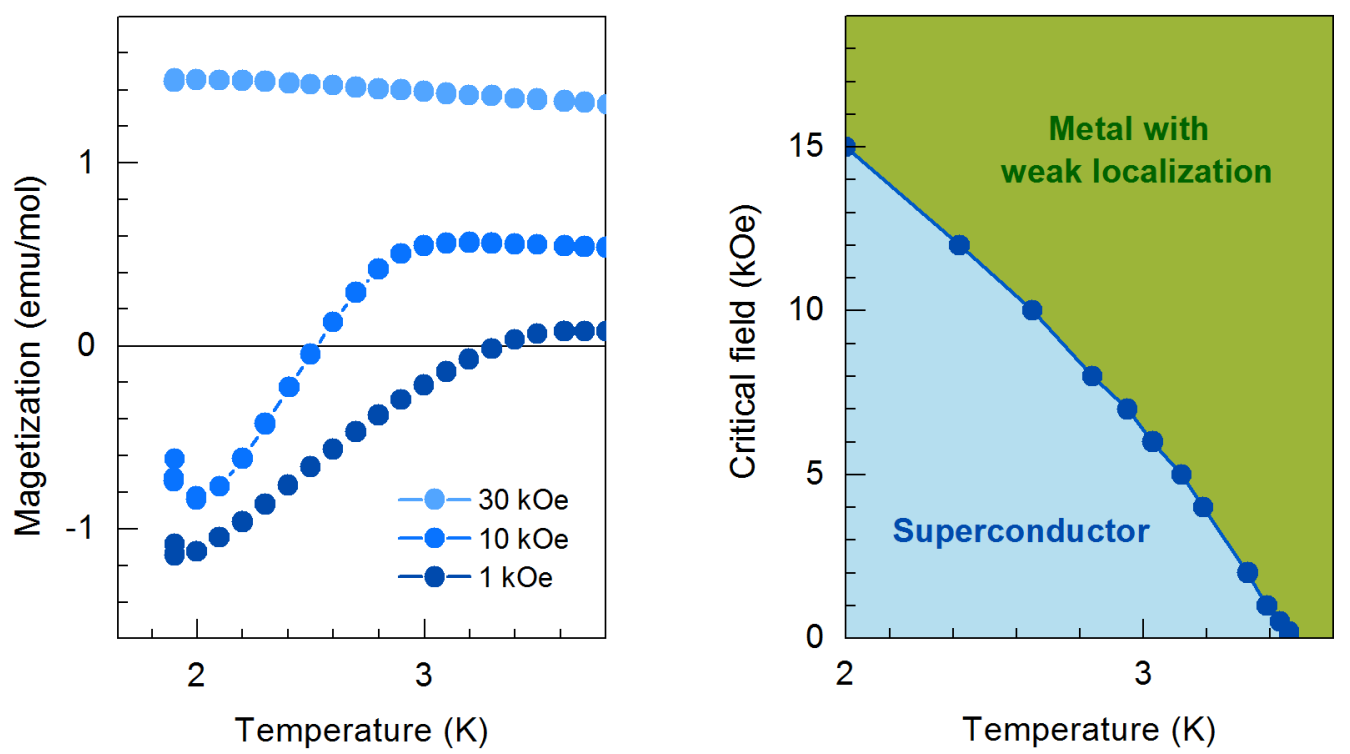

Figure 4. Superconducting transition at suppressed critical temperatures in the $\operatorname{Ti}(\mathrm{O}, \mathrm{N})$ nanoribbons. a, Comparison of temperature dependences of the magnetic susceptibility, $\chi(T)$, measured for the TiON-4/30 $(\bullet)$ and the TiON-30/30 $(\bullet)$ samples. The data is corrected for the diamagnetic core contributions of Ti, $\mathrm{O}$ and $\mathrm{N}$. The weak ferromagnetic-like increase in $\chi(T)$ and a splitting between data measured with the zero-field and field-cooling protocols is noticed for 
the TiON-4/30 sample. Inset: Magnetic hysteresis loop measured at $5 \mathrm{~K}$ corroborates with the weak ferromagnetic response for the TiON-4/30 sample. b, The low-temperature dependence of the superconducting $\mathbf{T i O N - 3 0 / 3 0}$ magnetization measured in different magnetic fields, up to 30 kOe. Please note the suppression of the superconducting critical temperature with the increasing magnetic field and a complete suppression of superconductivity for the highest field of $30 \mathrm{kOe}$. c, Temperature dependence of the critical field, which separates the low-temperature superconducting phase from the disordered metallic phase in TiON-30/30.

In the strongly nitridated TiON-30/30 sample, $\chi(T)$ is nearly temperature independent at $\chi=$ $5.7 \cdot 10^{-5} \mathrm{emu} / \mathrm{mol}$ between room temperature and $\sim 25 \mathrm{~K}$, which is the hallmark of a Pauli spin susceptibility and of a metallic state of the $\mathrm{Ti}(\mathrm{O}, \mathrm{N})$ nanoribbons with a low density of states at the Fermi level of only $N_{\mathrm{F}} \approx 1.7$ states/eV per formula unit. For comparison, standard bulk TiN has a significantly higher Pauli spin susceptibility of $\chi=1 \cdot 1 \cdot 10^{-4} \mathrm{emu} / \mathrm{mol}$ (Fig. S8) and a $N_{\mathrm{F}}$ value larger roughly for a factor of 2 . Below $\sim 25 \mathrm{~K}, \chi(T)$ of $\mathbf{T i O N - 3 0 / 3 0}$ increases slightly because of the weak Curie-like contribution $\left(C=8.4 \cdot 10^{-5} \mathrm{emu} \mathrm{K} / \mathrm{mol}\right)$ but then it sharply drops below the critical temperature $T_{\mathrm{c}}=3.5(1) \mathrm{K}$ as it becomes diamagnetic and thus signals the emergence of a superconducting phase (Fig. 4b). We note that the superconducting response cannot be simply attributed to the possible traces of elemental titanium, which has much lower $T_{\mathrm{c}}$ of about $0.5 \mathrm{~K}$, nor to any of the parasitic titania phases, which are all wide-gap semiconductors. The measured $T_{\mathrm{c}} \leq 3.5 \mathrm{~K}$ are lower compared to bulk TiN $\left(T_{\mathrm{c}} \approx 5.6 \mathrm{~K}\right)^{16,17}$ or even to stoichiometric TiN films, where it is about $4.5 \mathrm{~K} .{ }^{18-20}$ With application of a magnetic field, the superconducting response is rapidly suppressed and $T_{\mathrm{c}}$ decreases to $2.1 \mathrm{~K}$ in the magnetic field of $15 \mathrm{kOe}$ (Fig. 4c), yielding the superconducting coherence length ${ }^{41} \xi(2.1 \mathrm{~K}) \approx 15 \mathrm{~nm}$, which is 
comparable to a typical cross section of nanoribbons. In the fields of $30 \mathrm{kOe}$ or higher, $T_{\mathrm{c}}$ is so low that no superconducting response is observed within the experimentally accessible temperature range $(T \geq 1.9 \mathrm{~K})$. The rapid suppression of the superconducting $T_{\mathrm{c}}$ with the magnetic field and the very small difference between the zero-field-cooled and field-cooled measurements below $T_{\mathrm{c}}$ suggest that $\mathbf{T i O N - 3 0 / 3 0}$ is a Type I superconductor in agreement with the literature data on bulk analogues. ${ }^{16}$

The suppression of superconductivity in the $\mathrm{Ti}(\mathrm{O}, \mathrm{N})$ samples is correlated with the degree of disorder. One immediate observation is that the superconductivity is completely suppressed in the disordered samples with $\Delta>0.04 \AA$. Since susceptibility measurements reveal very low density of states as well as a presence of localized moments, we next studied how this is manifested in the transport properties. An example of an isolated nanoribbon of the superconducting TiON-30/30 sample together with four deposited Pt measuring contacts is shown in the inset of Fig. 5a. The room-temperature nanoribbon resistivity of $\rho=1760 \mu \Omega \mathrm{cm}$ is significantly higher than the typical resistivity of TiN films $\left(\rho \sim 100 \mu \Omega \mathrm{cm}^{42}\right)$. For a nanoribbon from a non-superconducting TiON-4/30 batch, the room temperature resistivity is even higher, $\rho=9670 \mu \Omega \mathrm{cm}$ (Fig. 5a). Strikingly, unlike in simple metals, the resistance of superconducting TiON-30/30 nanoribbon first increases with decreasing temperature (Fig. 5a). The moderate increase in resistance cannot be accounted for by the Arrhenius behavior $R(T) \propto \exp \left(T_{0} / T\right)$, characteristic of hopping type of conductivity. Instead, an excellent fit of $R(T)$ is obtained by considering the weak-localization corrections of the resistance $R_{0}$ with $R(T)=R_{0}(1+$ $\left.\frac{\rho_{e} e^{2}}{2 \pi \hbar S} L_{\varphi}\right)$. Here $L_{\varphi}$ is the temperature-dependent phase-breaking length, $S$ the nanoribbon crosssection and $\rho_{e}$ is the impurity scattering limited value of the resistivity. ${ }^{31,32}$ Unconstrained fit of 
the TiON-30/30 data between 300 and $50 \mathrm{~K}$ yields $L_{\varphi} \propto T^{-p}$ with a power-law exponent $p=$ $0.35(1)$, which matches the expected $p=1 / 3$ for dephasing via weakly inelastic electron-electron collisions in one-dimension. ${ }^{43,44} \mathrm{We}$ notice that $L_{\varphi}$ saturates at low-temperatures, a feature common for most one-dimensional nanostructures. ${ }^{32,45}$ Therefore, both the magnitude and the temperature dependence of $R(T)$ clearly speak for the pronounced effects of disorder leading to weak localization effects even in the nominally superconducting samples.

a

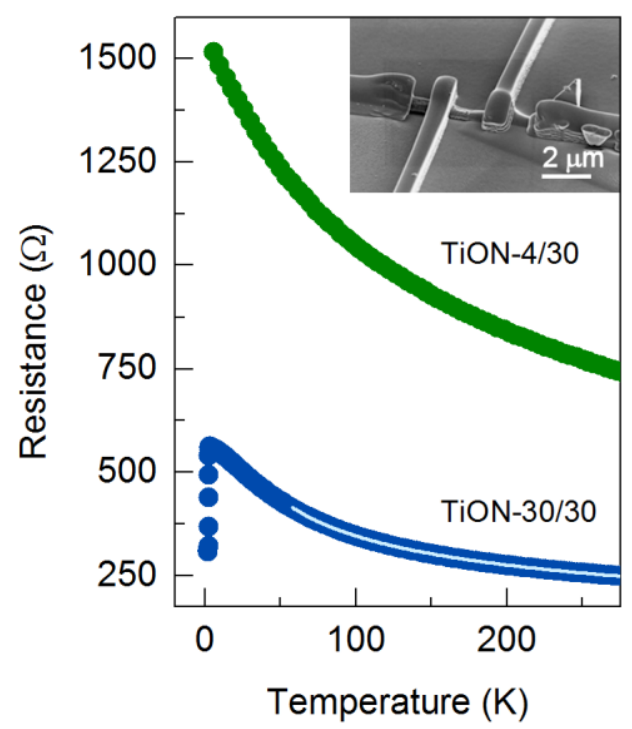

b

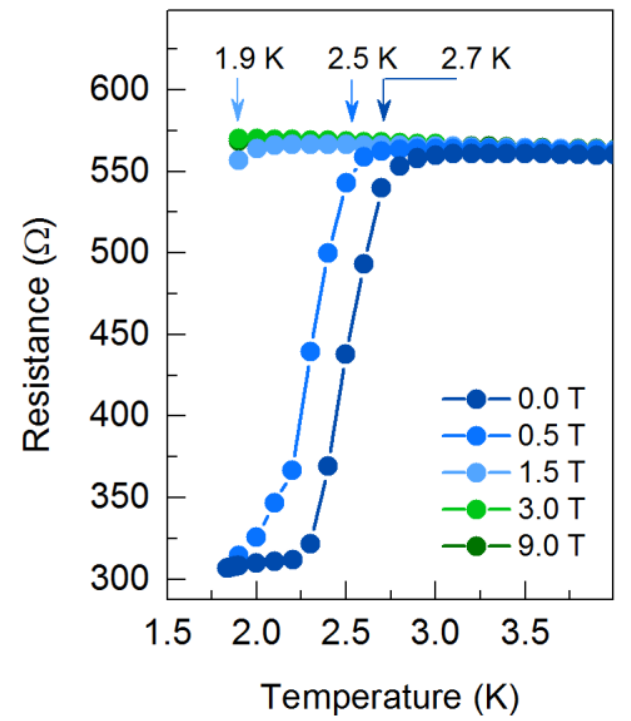

Figure 5. Weak localization effects and superconductivity of a single $\mathrm{Ti}(\mathrm{O}, \mathrm{N})$ nanoribbon. a, Temperature dependence of the resistance $R(T)$, as measured on a single nanoribbon selected from the TiON-30/30 $(\bullet)$ and TiON-4/30 $(\bullet)$ batches. The thick white line is a fit of TiON-30/30 data to $R(T)=R_{0}\left(1+A T^{-p}\right)$ with a power-law exponent of $p=0.35(1)$ and $R_{0}=24(1) \Omega$. This model is consistent with weak localization effects, where the temperature-dependent phasebreaking length is determined by the dephasing via weakly inelastic electron-electron collisions in one-dimension. Inset: Resistance was measured on a single nanoribbon with a $144 \mathrm{~nm} \times 680$ $\mathrm{nm}$ cross-section and a length that exceeds $3 \mu \mathrm{m}$. The distance between the two central $\mathrm{Pt}$ 
electrodes is $1.34 \mu \mathrm{m}$. Thus, the room-temperature resistance $R(300 \mathrm{~K})=241 \Omega$ thus yields a resistivity of $\rho=1760 \mu \Omega \mathrm{cm}$. b, Low-temperature resistance measured in different magnetic fields between 0 and $9 \mathrm{~T}$, where the rapid drop of $R(T)$ due to the onset of superconductivity systematically shifts to lower temperatures. For fields $B>1.5 \mathrm{~T}$, the superconducting transition escapes out of our experimentally accessible temperature range.

A sharp drop in resistance due to the superconducting transition is observed below the critical temperature $T_{\mathrm{c}}=2.8 \mathrm{~K}$ (Fig. $5 \mathrm{~b}$ ) for TiON-30/30. On the other hand, the transition is completely absent until $1.5 \mathrm{~K}$ for the non-superconducting TiON-4/30 nanoribbon where $R(T)$ continues to increase with decreasing temperature (Fig. 5a). The superconducting transition temperature for the TiON-30/30 nanoribbon is rapidly suppressed in the magnetic field thus mimicking the behavior observed in the magnetization measurements and affirming the superconducting origin of the resistivity drop. We note at this point that the critical temperature of the measured nanoribbon is slightly lower compared to the superconducting onset temperature of $3.5 \mathrm{~K}$, deduced from the magnetization measurements. The variation of $T_{\mathrm{c}}$ among different nanoribbons from the same batch (Fig. S9) could explain the width of the superconducting transition observed in magnetization measurements (Fig. 4). However, it cannot explain why the resistance of a single nanoribbon does not drop to zero, as expected for a conventional superconductor. A nonvanishing low-temperature resistance in very thin nanoribbons ${ }^{46}$ or in certain granular metal thin films ${ }^{47}$ was associated with thermal and quantum fluctuations of the order parameter. Alternatively, the residual low-temperature resistance can be also due to the conversion of the current conducted by normal electrons in the metallic lead to a current of Cooper pairs in the 
superconductor via Andreev reflection. ${ }^{48-50}$ A more detailed discussion of these possibilities will be published elsewhere.

\section{CONCLUSIONS}

The comprehensive experimental results allow us to propose a phase diagram for the $\mathrm{Ti}(\mathrm{O}, \mathrm{N})$ nanoribbon samples (Fig. 6) where we use the lattice parameter as an empirical control parameter of the electronic ground state. We stress that the lattice parameter is implicitly dependent on two key structural parameters, both controlled by the anion and the ion-vacancy diffusion: the level of nitridation and the concentration of ion vacancies. The XPS study proves that the nitridation level monotonically increases with the increasing reaction time and ammonia flow as nitrogen gradually substitutes oxygen in the $\mathrm{Ti}(\mathrm{O}, \mathrm{N})$ structure. As a result, the lattice expands (Fig. 6, middle panel). However, the variation of N/Ti ratio is still very limited in range - for most samples it ranges between $\sim 0.9$ and 1.1. Therefore, the level of nitridation alone cannot explain the enormous span of lattice parameters, which are in some cases even smaller than for the TiO standard. The other key parameter is the presence of ion vacancies. Because of the small nitride anion diffusion rate, samples prepared at short reaction times contain a large concentration of ion vacancies. With extended reaction time, these ion vacancies either diffuse to surface or are slowly occupied by incoming nitrogen species. As a result, the concentration of ion vacancies decreases and the lattice parameter approaches the Vegard's law values close to the optimal TiN composition. It is thus not surprising that $\Delta$ rapidly decreases as a function of $a$ (Fig. 6, top panel). The final question that remains is, which of the two parameters controls the superconductivity, which develops from the highly disordered metallic state. The answer is found by comparing the samples prepared in different ammonia flows, which show nominally 
nearly identical N/Ti ratio, but still have remarkably different lattice constants, e.g. the TiON10/25 and TiON-8/30 samples with $a=4.181 \AA$ and $4.207 \AA$ (Table S2). These samples differ only in the concentration of ion vacancies and exhibit drastically different $\Delta$ of 0.058 and 0.032 $\AA$, respectively. Yet the former sample shows no superconductivity, whereas the latter is a superconductor with $T_{\mathrm{c}}=2.5 \mathrm{~K}$. We thus conclude that the suppression of superconductivity in the $\operatorname{Ti}(\mathrm{O}, \mathrm{N})$ nanoribbons is mainly caused by the injection of ion vacancies during the chemical conversion to oxynitride structure. We note that these findings are directly relevant for the observed disorder-driven direct superconductor-to-insulator transition in two-dimensional TiN thin films ${ }^{21,22}$, since ion vacancies are defining the disorder strength and driving this highly intriguing transition.

The present study demonstrates that anion exchange can be a very efficient tool for controlling the chemical composition and the disorder strength of nanomaterials. Here we manipulated $\mathrm{Ti}(\mathrm{O}, \mathrm{N})$ nanoribbons to switch them from highly-disordered metallic state to superconducting state. However, such approach to control the electronic state of nanoparticles may be much more versatile and could be applied to a number of semiconducting and metallic nanostructures where ion and ion-vacancy diffusion drive the chemical conversion process. ${ }^{1-14}$ 
Lattice constant $(\AA)$

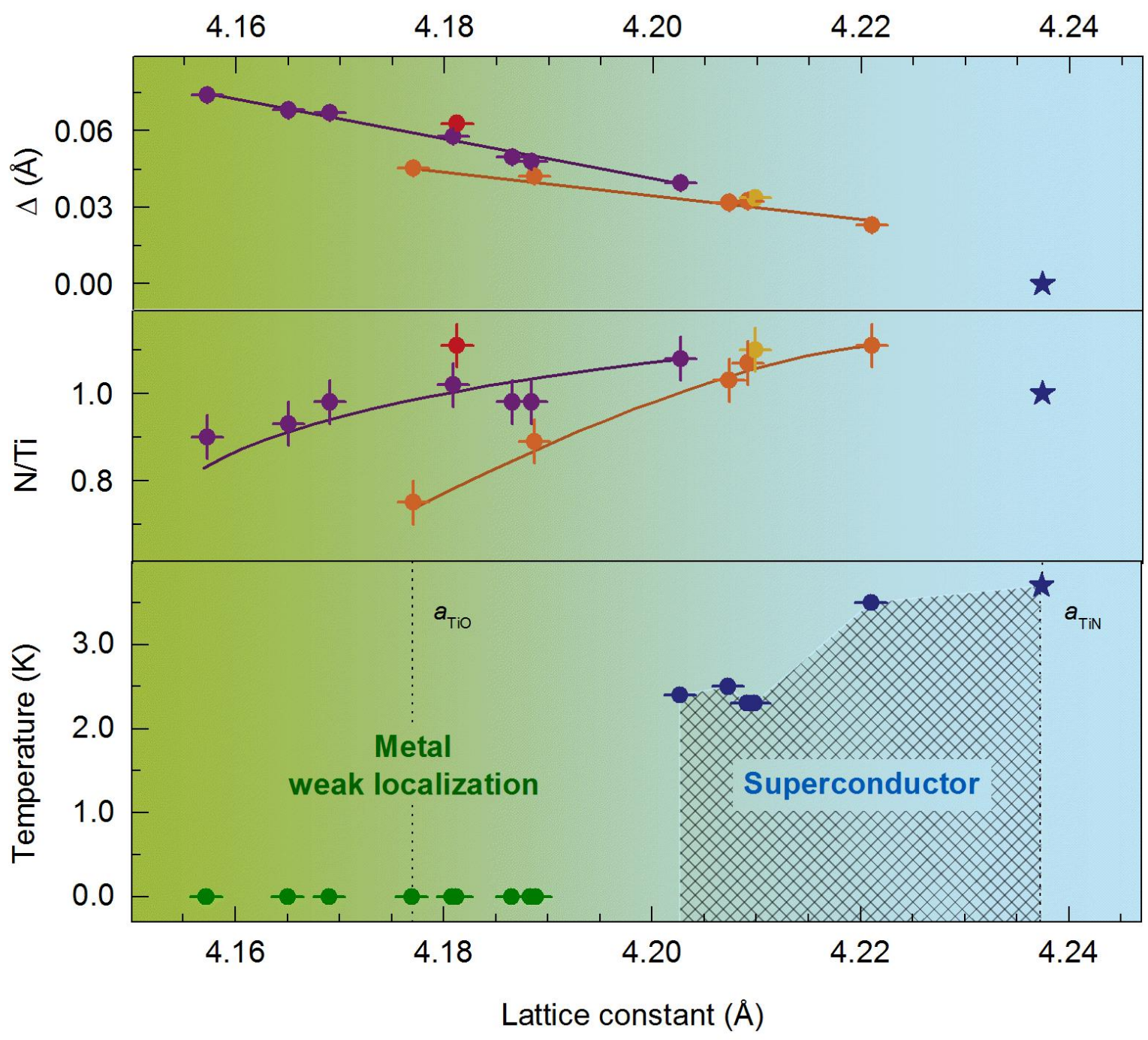

Figure 6. Effect of disorder on the electronic properties of the $\operatorname{Ti}(\mathrm{O}, \mathrm{N})$ nanoribbons. Electronic phase diagram of oxynitride nanoribbons (bottom panel) showing the evolution of superconducting critical temperatures, $T_{\mathrm{c}},(\bullet)$ as a function of the lattice parameter. No superconductivity has been observed for the samples with $a<4.19 \AA$. With increasing lattice constant, the N/Ti ratio deduced from the XPS data systematically increases (middle panel). However, the $\mathrm{N} / \mathrm{Ti}$ ratio is also $\mathrm{NH}_{3}(\mathrm{~g})$ flow dependent (compare $\bullet$ and $\bullet$ circles, which stand for 
the experiments with ammonia flows of 25 and $30 \mathrm{~mL} / \mathrm{min}$, respectively), as the $\mathrm{NH}_{3}(\mathrm{~g})$ flow additionally affects the concentration of ion vacancies at different stages of transformation. The deviation of the experimental lattice constant from the values calculated from the Vegard's law, $\Delta$, is a direct measure of the disorder strength related to the concentration of ion vacancies (top panel). The superconducting samples are those, where the disorder is sufficiently weak, i.e. in samples with $\Delta<0.04 \AA$. 


\section{Methods}

Sample preparation. The $\mathrm{Ti}(\mathrm{O}, \mathrm{N})$ nanoribbon samples were prepared by calcination of $225 \mathrm{mg}$ hydrogen titanate nanoribbons (HTiNRs) in a mixture of $\mathrm{NH}_{3}(\mathrm{~g}) / \mathrm{Ar}(\mathrm{g})$ flow at $800{ }^{\circ} \mathrm{C}$ for different reaction times. The flow ratio of $\mathrm{NH}_{3}(\mathrm{~g}) / \mathrm{Ar}(\mathrm{g})$ was set to either to $25 \mathrm{~mL} \mathrm{~min} / 15 \mathrm{ml}$ $\min ^{-1}$ or to $30 \mathrm{~mL} \mathrm{~min}^{-1} / 10 \mathrm{~mL} \mathrm{~min}^{-1}$. Additionally, two samples were prepared at higher values of $\mathrm{NH}_{3}(\mathrm{~g})$ flow, 100 and $150 \mathrm{~mL} / \mathrm{min}$, respectively. The samples' labels and exact reaction conditions are summarized in Table S1. The first number in the samples' labels, for example in TiON-4/30, indicates the reaction time $(4 \mathrm{~h})$, while the last number refers to the value of the ammonia flow $(30 \mathrm{~mL} / \mathrm{min})$. In addition, $\mathrm{TiO}_{2}$ nanoribbons were also synthesized from HTiNRs ( $m=225 \mathrm{mg}$ ) by calcination in $\mathrm{NH}_{3}(\mathrm{~g}) / \mathrm{Ar}(\mathrm{g})$ flow as follows. When the calcination temperature reached the highest temperature of $800{ }^{\circ} \mathrm{C}$, the sample was immediately cooled back to the room temperature in $\operatorname{Ar}(\mathrm{g})$ flow set to $10 \mathrm{~mL} \mathrm{~min}^{-1}$. The reference $\mathrm{TiN}$ bulk powder was purchased from Sigma-Aldrich.

Measurements. The structural analysis was performed on a cut surface by powder X-ray powder diffraction (XRD) using $\mathrm{Cu} \mathrm{K}$ 等adiation $(\lambda=1.5406 \AA)$ and a Sol-X energy-dispersive detector (Endeavor D4, Bruker AXS, Karlsruhe, Germany). The angular range $2 \theta$ was set from 5 to $60^{\circ}$ with a step size of $0.02^{\circ}$ and a collection time of $3 \mathrm{~s}$.

The morphology of the parent HTiNRs and prepared $\mathrm{Ti}(\mathrm{O}, \mathrm{N})$ nanoribbons was investigated with field emission scanning (FE-SEM, Jeol, 7600F) and transmission (TEM, Jeol 2100) electron microscopes. High resolution transmission electron microscopy (HRTEM) and Electron Energy Loss Spectroscopy (EELS) observations were performed using a field emission transmission electron microscope JEOL 2200 FS operating at $200 \mathrm{kV}$ with the spatial resolution of $0.19 \mathrm{~nm}$. 
The microscope is equipped with an in-column filter (Omega Filter). The EELS maps were obtained with the three window method on the $\mathrm{K}$ edges at $401 \mathrm{eV}$ and $530 \mathrm{eV}$ for nitrogen and oxygen, respectively, and the L2/L3 edges at $460 \mathrm{eV} / 466 \mathrm{eV}$ for titanium. A semi quantification EELS was also performed on these edges.

For the determining the nitrogen content, X-ray photoelectron spectroscopy (XPS) measurements were performed with a VERSAPROBE PHI 5000 from Physical Electronics, equipped with a monochromatic $\mathrm{Al} \mathrm{K} \alpha \mathrm{X}$-ray source. The energy resolution was $0.6 \mathrm{eV}$. A dual beam charge neutralizator composed of an electron gun (ca. $1 \mathrm{eV})$ and an $\mathrm{Ar}$ ion gun $(\leq 10 \mathrm{eV})$ was used in order to compensate the built-up charge on the surface of the specimens during the measurements. The specimens for the XPS measurements were prepared by pressing the specimen into a pellet. A conductive double-sided tape was used to attach the pellet to a sample holder.

Magnetization was measured on powder samples between $1.9 \mathrm{~K}$ and $300 \mathrm{~K}$ in magnetic fields up to 50 kOe with Quantum Design MPMS-XL-5 SQUID magnetometer. The raw data were corrected for the sample holder contribution and for temperature independent Larmor diamagnetism, as calculated from Pascal's tables.

For resistivity measurements, $\operatorname{Ti}(\mathrm{O}, \mathrm{N})$ nanoribbons were dispersed in acetonitrile in an ultrasonic bath at $80 \mathrm{kHz}$ for 5 minutes. The resulting dispersion was drop-cast on a silica substrate and examined under SEM. Focused Ion Beam (FIB) induced platinum deposition was achieved using beams with $30 \mathrm{kV}$ acceleration voltage and a current of $80-430 \mathrm{pA}$ with a FEI Helios NanoLab 600i. The thickness of the Pt deposition was roughly $1 \mu \mathrm{m}$ and was chosen to make the contacts strong enough to withstand the mechanical strain caused by the differential contraction of the sample and substrate during the cooling to low temperatures. The temperature 
and magnetic field dependent electrical measurements were performed on a Quantum Design Physical Properties Measuring System (PPMS) in the temperature range from 300 to $2 \mathrm{~K}$ and in magnetic fields from 0 to $9 \mathrm{~T}$ respectively. The thickness and the length of the measured $\mathrm{Ti}(\mathrm{O}, \mathrm{N})$ nanoribbons was controlled by using a Veeco Dimension 3100 Atomic Force Microscope.

Acknowledgment. C. Bittencourt is Research Associate of the National Funds for Scientific Research (FRS-FNRS, Belgium). M. Sluban, P. Umek and M. H. Delville acknowledge financial support from the COST action MP1202 "HINT".

Supporting Information Available. Additional experimental, microscopic, XRD and susceptibility data are provided. The Supporting Information is available free of charge on the ACS Publication website at DOI: xxxxx.

\section{References}

(1) Yin, Y.; Rioux, R. M.; Erdonmez, C. K.; Hughes, S.; Somorjai, G. A.; Alivisatos, A. P. Formation of Hollow Nanocrystals Through the Nanoscale Kirkendall Effect. Science 2004, 304, 711-714.

(2) Fan, H. J.; Knez, M.; Scholz, R.; Nielsch, K.; Pippel, E.; Hesse, D.; Zacharias, M.; Gösele, U. Monocrystalline Spinel Nanotube Fabrication Based on the Kirkendall Effect. Nat. Mater. 2006, 5, 627-631.

(3) González, E.; Arbiol, J.; Puntes, V. F. Carving at the Nanoscale: Sequential Galvanic Exchange and Kirkendall Growth at Room Temperature. Science 2011, 334, 1377-1380.

(4) Wang, J. X.; Ma, C.; Choi, Y.; Su, D.; Zhu, Y.; Liu, P.; Si, R.; Vukmirovic, M. B.; Zhang, Y.; Adzic, R. R. Kirkendall Effect and Lattice Contraction in Nanocatalysts: A New Strategy to Enhance Sustainable Activity. J. Am. Chem. Soc. 2011, 133, 13551-13557.

(5) Park, M.-H.; Cho, Y.; Kim, K.; Kim, J.; Liu, M.; Cho, J. Germanium Nanotubes Prepared by Using the Kirkendall Effect as Anodes for High-Rate Lithium Batteries. Angew. Chem. - Int. Ed. 2011, 50, 9647-9650.

(6) Wang, W.; Dahl, M.; Yin, Y. Hollow Nanocrystals through the Nanoscale Kirkendall Effect. Chem. Mater. 2013, 25, 1179-1189. 
(7) Yin, Y.; Erdonmez, C. K.; Cabot, A.; Hughes, S.; Alivisatos, A. P. Colloidal Synthesis of Hollow Cobalt Sulfide Nanocrystals. Adv. Funct. Mater. 2006, 16, 1389-1399.

(8) Railsback, J. G.; Johnston-Peck, A. C.; Wang, J.; Tracy, J. B. Size-Dependent Nanoscale Kirkendall Effect During the Oxidation of Nickel Nanoparticles. ACS Nano 2010, 4, 1913-1920.

(9) El Mel, A.-A.; Buffière, M.; Tessier, P.-Y.; Konstantinidis, S.; Xu, W.; Du, K.; Wathuthanthri, I.; Choi, C.-H.; Bittencourt, C.; Snyders, R. Highly Ordered Hollow Oxide Nanostructures: The Kirkendall Effect at the Nanoscale. Small 2013, 9, 2838-2843.

(10) Fan, H. J.; Gösele, U.; Zacharias, M. Formation of Nanotubes and Hollow Nanoparticles Based on Kirkendall and Diffusion Processes: A Review. Small 2007, 3, 1660-1671.

(11) Park, J.; Zheng, H.; Jun, Y.; Alivisatos, A. P. Hetero-Epitaxial Anion Exchange Yields Single-Crystalline Hollow Nanoparticles. J. Am. Chem. Soc. 2009, 131, 13943-13945.

(12) Xia, X.; Zhu, C.; Luo, J.; Zeng, Z.; Guan, C.; Ng, C. F.; Zhang, H.; Fan, H. J. Synthesis of Free-Standing Metal Sulfide Nanoarrays via Anion Exchange Reaction and Their Electrochemical Energy Storage Application. Small 2014, 10, 766-773.

(13) Zhao, W.; Zhang, C.; Geng, F.; Zhuo, S.; Zhang, B. Nanoporous Hollow Transition Metal Chalcogenide Nanosheets Synthesized via the Anion-Exchange Reaction of Metal Hydroxides with Chalcogenide Ions. ACS Nano 2014, 8, 10909-10919.

(14) Anderson, B. D.; Tracy, J. B. Nanoparticle Conversion Chemistry: Kirkendall Effect, Galvanic Exchange, and Anion Exchange. Nanoscale 2014, 6, 12195-12216.

(15) Patsalas, P.; Logothetidis, S. Optical, Electronic, and Transport Properties of Nanocrystalline Titanium Nitride Thin Films. J. Appl. Phys. 2001, 90, 4725-4734.

(16) Matthias, B. T.; Geballe, T. H.; Compton, V. B. Superconductivity. Rev. Mod. Phys. 1963, $35,1-22$.

(17) Toth, L. E. Transition Metal Carbides and Nitrides; Academic Press: New York, 1971.

(18) Vissers, M. R.; Gao, J.; Wisbey, D. S.; Hite, D. A.; Tsuei, C. C.; Corcoles, A. D.; Steffen, M.; Pappas, D. P. Low Loss Superconducting Titanium Nitride Coplanar Waveguide Resonators. Appl. Phys. Lett. 2010, 97, 232509.

(19) Goupy, J.; Djemia, P.; Pouget, S.; Belliard, L.; Abadias, G.; Villégier, J. C.; Sauvageot, J. L.; Pigot, C. Structure, Electrical Conductivity, Critical Superconducting Temperature and Mechanical Properties of $\mathrm{TiN}_{\mathrm{x}} \mathrm{O}_{\mathrm{y}}$ Thin Films. Surf. Coat. Technol. 2013, 237, 196-204.

(20) Ohya, S.; Chiaro, B.; Megrant, A.; Neill, C.; Barends, R.; Chen, Y.; Kelly, J.; Low, D.; Mutus, J.; O’Malley, P. J. J.; et al. Room Temperature Deposition of Sputtered TiN Films for Superconducting Coplanar Waveguide Resonators. Supercond. Sci. Technol. 2014, 27, 015009.

(21) Baturina, T. I.; Mironov, A. Y.; Vinokur, V. M.; Baklanov, M. R.; Strunk, C. Localized Superconductivity in the Quantum-Critical Region of the Disorder-Driven Superconductor-Insulator Transition in TiN Thin Films. Phys. Rev. Lett. 2007, 99, 257003.

(22) Baturina, T. I.; Postolova, S. V.; Mironov, A. Y.; Glatz, A.; Baklanov, M. R.; Vinokur, V. M. Superconducting Phase Transitions in Ultrathin TiN Films. EPL Europhys. Lett. 2012, 97, 17012.

(23) Ohno, H. Making Nonmagnetic Semiconductors Ferromagnetic. Science 1998, 281, 951956.

(24) Matsumoto, Y.; Murakami, M.; Shono, T.; Hasegawa, T.; Fukumura, T.; Kawasaki, M.; Ahmet, P.; Chikyow, T.; Koshihara, S.-Y.; Koinuma, H. Room-Temperature 
Ferromagnetism in Transparent Transition Metal-Doped Titanium Dioxide. Science 2001, $291,854-856$.

(25) Cao Khang, N.; Van Khanh, N.; Hoai Anh, N.; Thi Nga, D.; Van Minh, N. The Origin of Visible Light Photocatalytic Activity of N-Doped and Weak Ferromagnetism of Fe-Doped $\mathrm{TiO}_{2}$ Anatase. Adv. Nat. Sci. Nanosci. Nanotechnol. 2011, 2, 015008.

(26) Wen, Q.-Y.; Zhang, H.-W.; Yang, Q.-H.; Jing, Y.-L.; Zhang, P.-X. Ferromagnetism in Nitrogen-Doped $\mathrm{TiO}_{2}$ Nanoparticles. IEEE Trans. Magn. 2011, 47, 3987-3990.

(27) Zukalova, M.; Prochazka, J.; Bastl, Z.; Duchoslav, J.; Rubacek, L.; Havlicek, D.; Kavan, L. Facile Conversion of Electrospun $\mathrm{TiO}_{2}$ into Titanium Nitride/Oxynitride Fibers. Chem. Mater. 2010, 22, 4045-4055.

(28) Wei, Y.-J.; Peng, C.-W.; Cheng, T.-M.; Lin, H.-K.; Chen, Y.-L.; Lee, C.-Y.; Chiu, H.-T. Conversion of Potassium Titanate Nanowires into Titanium Oxynitride Nanotubes. ACS Appl. Mater. Interfaces 2011, 3, 3804-3812.

(29) Umek, P.; Cevc, P.; Jesih, A.; Gloter, A.; Ewels, C. P.; Arčon, D. Impact of Structure and Morphology on Gas Adsorption of Titanate-Based Nanotubes and Nanoribbons. Chem. Mater. 2005, 17, 5945-5950.

(30) Rutar, M.; Rozman, N.; Pregelj, M.; Bittencourt, C.; Cerc Korošec, R.; Sever Škapin, A.; Mrzel, A.; Škapin, S. D.; Umek, P. Transformation of Hydrogen Titanate Nanoribbons to $\mathrm{TiO}_{2}$ Nanoribbons and the Influence of the Transformation Strategies on the Photocatalytic Performance. Beilstein J. Nanotechnol. 2015, 6, 831-844.

(31) Heremans, J. P.; Thrush, C. M.; Morelli, D. T.; Wu, M.-C. Resistance, Magnetoresistance, and Thermopower of Zinc Nanowire Composites. Phys. Rev. Lett. 2003, 91, 076804.

(32) Liang, D.; Sakr, M. R.; Gao, X. P. A. One-Dimensional Weak Localization of Electrons in a Single InAs Nanowire. Nano Lett. 2009, 9, 1709-1712.

(33) Umek, P.; Bittencourt, C.; Guttmann, P.; Gloter, A.; Škapin, S. D.; Arčon, D. Mn ${ }^{2+}$ Substitutional Doping of $\mathrm{TiO}_{2}$ Nanoribbons: A Three-Step Approach. J. Phys. Chem. C 2014, 118, 21250-21257.

(34) Kamiya, K.; Yoko, T.; Bessho, M. Nitridation of $\mathrm{TiO}_{2}$ Fibres Prepared by the Sol-Gel Method. J. Mater. Sci. 1987, 22, 937-941.

(35) Chen, T.-T.; Liu, H.-P.; Wei, Y.-J.; Chang, I.-C.; Yang, M.-H.; Lin, Y.-S.; Chan, K.-L.; Chiu, H.-T.; Lee, C.-Y. Porous Titanium Oxynitride Sheets as Electrochemical Electrodes for Energy Storage. Nanoscale 2014, 6, 5106-5109.

(36) Drygaś, M.; Czosnek, C.; Paine, R. T.; Janik, J. F. Two-Stage Aerosol Synthesis of Titanium Nitride TiN and Titanium Oxynitride $\mathrm{TiO}_{\mathrm{x}} \mathrm{N}_{\mathrm{y}}$ Nanopowders of Spherical Particle Morphology. Chem. Mater. 2006, 18, 3122-3129.

(37) Martínez-Ferrero, E.; Sakatani, Y.; Boissière, C.; Grosso, D.; Fuertes, A.; Fraxedas, J.; Sanchez, C. Nanostructured Titanium Oxynitride Porous Thin Films as Efficient VisibleActive Photocatalysts. Adv. Funct. Mater. 2007, 17, 3348-3354.

(38) Djéga-Mariadassou, G.; Shin, C.-H.; Bugli, G. Tamaru's Model for Ammonia Decomposition over Titanium Oxynitride. J. Mol. Catal. Chem. 1999, 141, 263-267.

(39) Han, J. H.; Bang, J. H. A Hollow Titanium Oxynitride Nanorod Array as an Electrode Substrate Prepared by the Hot Ammonia-Induced Kirkendall Effect. J. Mater. Chem. A 2014, 2, 10568-10576.

(40) Bittencourt, C.; Rutar, M.; Umek, P.; Mrzel, A.; Vozel, K.; Arčon, D.; Henzler, K.; Krüger, P.; Guttmann, P. Molecular Nitrogen in N-Doped $\mathrm{TiO}_{2}$ Nanoribbons. RSC Adv. 2015, 5, 23350-23356. 
(41) Saha, N. C.; Tompkins, H. G. Titanium Nitride Oxidation Chemistry: An X-ray Photoelectron Spectroscopy Study. J. Appl. Phys. 1992, 72, 3072-3079.

(42) Annett, J. F. Superconductivity, Superfluids, and Condensates; First Edition edition.; Oxford University Press: Oxford ; New York, 2004.

(43) Leduc, H. G.; Bumble, B.; Day, P. K.; Eom, B. H.; Gao, J.; Golwala, S.; Mazin, B. A.; McHugh, S.; Merrill, A.; Moore, D. C.; et al. Titanium Nitride Films for Ultrasensitive Microresonator Detectors. Appl. Phys. Lett. 2010, 97, 102509.

(44) Wind, S.; Rooks, M. J.; Chandrasekhar, V.; Prober, D. E. One-Dimensional ElectronElectron Scattering with Small Energy Transfers. Phys. Rev. Lett. 1986, 57, 633-636.

(45) Kramer, B.; MacKinnon, A. Localization: Theory and Experiment. Rep. Prog. Phys. 1993, 56, 1469.

(46) Rueß, F. J.; Weber, B.; Goh, K. E. J.; Klochan, O.; Hamilton, A. R.; Simmons, M. Y. OneDimensional Conduction Properties of Highly Phosphorus-Doped Planar Nanowires Patterned by Scanning Probe Microscopy. Phys. Rev. B 2007, 76, 085403.

(47) Arutyunov, K. Y.; Golubev, D. S.; Zaikin, A. D. Superconductivity in One Dimension. Phys. Rep. 2008, 464, 1-70.

(48) Jaeger, H. M.; Haviland, D. B.; Orr, B. G.; Goldman, A. M. Onset of Superconductivity in Ultrathin Granular Metal Films. Phys. Rev. B 1989, 40, 182-196.

(49) Beenakker, C. W. J. Why Does a Metal—Superconductor Junction Have a Resistance? In Quantum Mesoscopic Phenomena and Mesoscopic Devices in Microelectronics; Kulik, I. O.; Ellialtioğlu, R., Eds.; NATO Science Series; Springer Netherlands, 2000; pp. 51-60.

(50) Beenakker, C. W. J. Random-Matrix Theory of Quantum Transport. Rev. Mod. Phys. 1997, 69, 731-808.

(51) Boogaard, G. R.; Verbruggen, A. H.; Belzig, W.; Klapwijk, T. M. Resistance of Superconducting Nanowires Connected to Normal-Metal Leads. Phys. Rev. B 2004, 69, 220503. 